DOI: 10.20472/IAC.2017.034.025

TIPAPORN KANJANARACH

Khon Kaen University, Thailand

NANTAWAN PANPECH

Khon Kaen University, Thailand

PANAYA CHOUWAJAREON

Khon Kaen University, Thailand

THANAPORN WISETGEAW

Khon Kaen University, Thailand

\title{
A SCOPING STUDY OF RESEARCH INTO THAI MEDICINAL PLANTS AND THAI TRADITIONAL DRUGS
}

\begin{abstract}
:
Introduction: Thailand established a policy to promote the use of traditional medical knowledge in the country's health care system in1977. Research into the safety and efficacy of Thai medicinal plants and Thai traditional drugs was a key strategy. Objective: This scoping review aimed to analyze the types of research articles specific to Thai medicinal plants and Thai traditional drugs. Methods: Research articles were extracted from three data bases: PubMed, Thai-journal citation index centre ( $\mathrm{TCl}$ ) and Thai Thesis Database. The keyword "Thai traditional*" was used to capture all possible articles. Three reviewers independently screened the search results to exclude the articles published in languages other than Thai or English, or references to other Thai traditional medical practice. Results: Of 1830 articles possibly related to Thai traditional drugs, 408 were finally included for the review. A majority of the articles were about individual Thai herbs. Only 46 (11.3\%) were about Thai traditional formulations. Seventy seven articles (18.9\%) were on herbs or Thai traditional formulations listed in the national essential drug list. Most of the research reports were in vitro phase (324 articles, $79.4 \%$ ) followed by in vivo phase (61 articles, $15.0 \%$ ), clinical phase I to phase III (10 articles, $2.45 \%$ ), biological activity (10 articles, $2.45 \%$ ) and post-marketing studies (3 articles, $0.7 \%$ ). An increasing trend of the number of publications started to be noticed after 2003. During 2012-2016, the average number of publications per year was 35. Conclusion: The findings suggested that evidence to support the use of Thai medicinal plants and Thai traditional drugs is still lacking. Thailand should review the country's strategies to support research into Thai medicinal plants and Thai traditional drugs.
\end{abstract}

\section{Keywords:}

natural product; herb; traditional medicine; health care policy; Thai

JEL Classification: 118 